\title{
The Analysis of Multilevel Technology for BLDC Motor of Electric Vehicle
}

\author{
Xingwang Zhang ${ }^{\mathrm{a}}$, Ran Zhao ${ }^{\mathrm{b}}$ \\ Nanchang Technology of Institute, Nanchang 330099,China



Keywords: BLDC In-wheel Motor, Electric Vehicle, Multilevel Inverter, Direct torque control.

\begin{abstract}
This paper presents the analysis of multilevel technology for electric vehicle BLDC motor Drive. The topology of multilevel inverter including three-level, five-level and seven-level inverter are discussed, and the general method of SVPWM for multilevel inverter are given. Based on the proposed vector select technique the direct torque control using multilevel inverter was designed for BLDC motor. To testify the given method the simulation are built using MATLAB/Simulink software. The output harmonic of the multilevel inverter are compared , and the flux linkage of BLDC motor driving by different level inverter are obtained. The results illustrated that the proposed SVPWM and DTC method can deduce the output harmonic and improve the motor control performance. It meanwhile using multilevel technology can increase the efficiency of the electric vehicle driving system.
\end{abstract}

\section{Introduction}

In recent years, electric vehicles seem to constitute an increasingly effective alternative to conventional vehicles in the effort to reduce harmful greenhouse gas emissions, while also reducing the dependence on imported petroleum for use by the transport sector. Because this, many automotive manufacturers began to development different types of electric vehicles include battery electric vehicles and plug-in hybrid electric vehicles. All of the components in an electric drive conversion, the motor is probably the most important. Because the motor has the most influence on the performance (speed, acceleration, efficiency) of the converted vehicle.

For now, the BLDC motor is most popular in the EV applications because its low cost and high efficiency ${ }^{[1]}$.However, there is still several problems in a BLDC drive.As shown in Fig.1, a conventional tow-level inverter driving BLDC motor seems to be a very interesting solution in automotive drive. But it takes problems for this application, like the high voltage change rates $(d v / d t)^{[2]}$, the output voltage harmonic and the EMI.



Fig.1 The Tow-Level Inverter for BLDC Motor Drive

To resovle these problems,The multilevel inverter is used to instead of the troditional 2-level


drive applications because of its low EMI and high efficiency. Direct Torque Control (DTC) is one of the most popular control strategies in high-performance variable-speed drive applications for induction machines, which it can decouple the interaction between flux and torque control, and provide good torque response in steady state and transient operation conditions ${ }^{[6-8]}$.

In this paper, the multilevel technology is proposed for electric vehicle BLDC motor Drive.The topology of multilevel inverter including three-level, five-level and seven-level inverter are 
discussed. A general method of DTC-SVM are given for motor control.At last, the simulation has been done by simulation, the EMI and linkage flux tracjient of the motor has been given.

\section{The Multilevel Technology}

The multilevel voltage source inverter's unique structure allows them to reach high voltage and power levels without the use of transfers. As the number of levels increases, the synthesized output waveform has more steps, which produces a staircase wave that approaches the desired waveform. Also as more steps are added to the waveform, the harmonic distortion of the output wave decreases ${ }^{[9]}$.Fig. 2 shows the three-level, five-level and seven level diode clamped inverter.



(b)

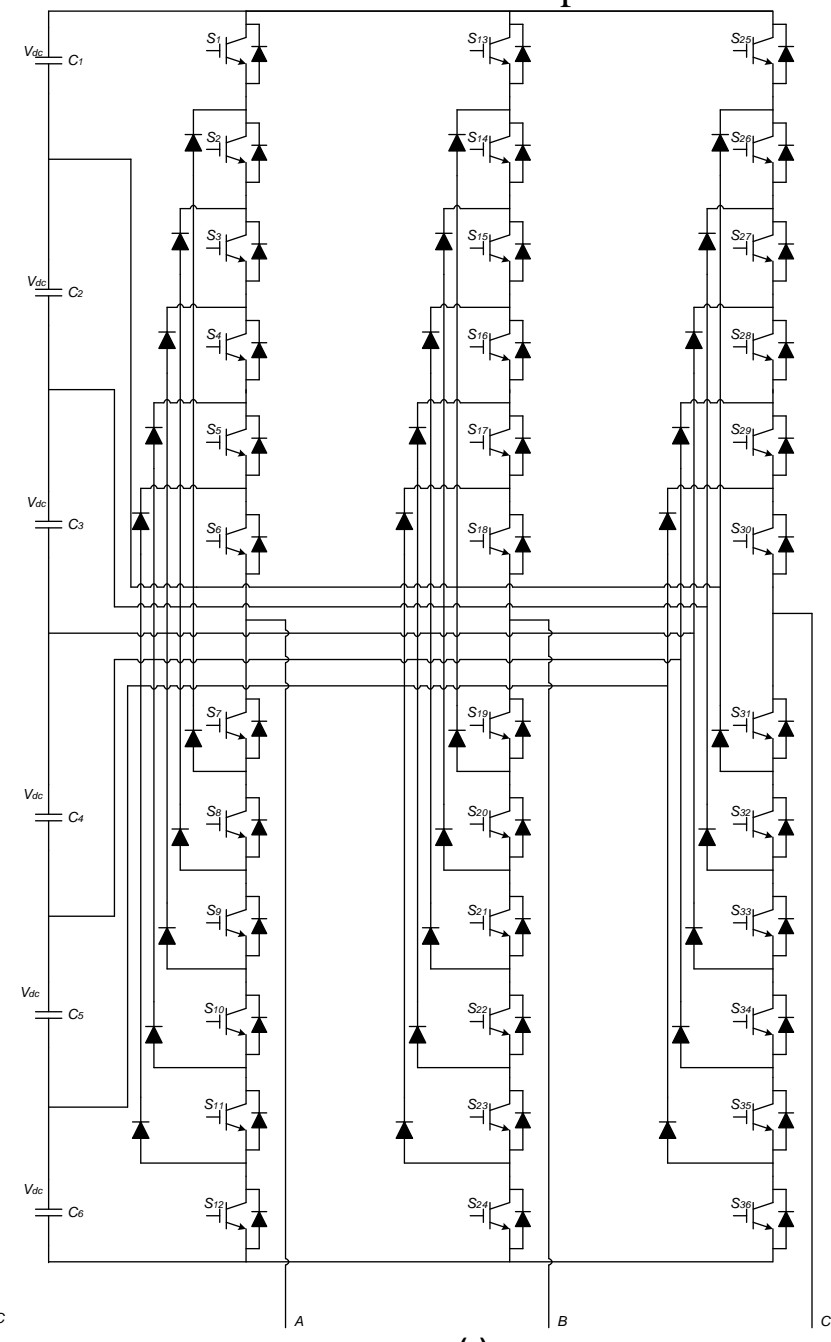

(c)

Fig.2 Topology of Multilevel Inverter :(a)Three-level (b)Five-level (c)Seven-level

The circuit model of BLDC motor is shown in Fig.1, the model equation of coltage can be defined as ${ }^{[10]}$ :

$v_{i}=R i_{i}+(L-M) \frac{d}{d t} i_{i}+e_{i}+v_{m}$

where $v_{i}(i=a, b, c)$ and $e_{i}$ are the voltage of the motor terminal and the back-emf voltage, $L$ and $M$ are the stator self and the mutual inductances and $v_{m}$ is the neutral voltage of the motor.

It has been proved that in order to control the fundamental output voltage and eliminate $n$ harmonics, therefore $n+1$ equations are needed. Therefore, multilevel inverter can provide the control of the fundamental component beside the ability to eliminate or control the amplitudes of two harmonics, not necessarily to be consecutive. The Fourier series expansion of the output voltage waveform is as follows ${ }^{[11]}$ :

$$
h_{\alpha}=\frac{4}{n \pi} \sum_{k=1}^{m}\left[V_{k} \cos (n \omega t)\right]
$$


where $V_{k}$ is the $k^{\text {th }}$ level of dc voltage, $n$ is an odd harmonic order, $m$ is the number of switching angles, and $\alpha_{k}$ is the switching angle. And $\alpha_{1}$ to $\alpha_{m}$ must satisfy $\alpha_{1}<\alpha_{2}<\alpha_{3}<\ldots<\alpha_{m}<\pi / 2$.

\section{Principles of The SVPWM and DTC}

The basic idea of voltage space vector modulation is to control the inverter output voltages so that their Parks representation will be approximately equals the reference voltage vector. The SVM technique can be easily extended to all multilevel inverters.



Fig.3 Space Vector Diagram of Multilevel Inverter

In the case of two level inverter, the output of each phase will be either $+V_{\mathrm{dc}} / 2$ or $-\mathrm{V}_{\mathrm{dc}} / 2$.The SVM technique can be easily extended to all multilevel inverters.Fig.3 shows space vectors for the traditional two-, three-, five- and seven-level inverters. These vector diagrams are universal regardless of the type of multilevel inverter. The adjacent three vectors can synthesize a desired voltage vector by computing the duty cycle $\left(T_{j}, T_{j+1}\right.$ and $\left.T_{j+2}\right)$ for each vector:

$$
V^{*}=\frac{\left(T_{j} V_{j}+T_{j+1} V_{j+1}+T_{j+2} V_{j+2}\right)}{T}
$$

The stator of a general BLDC motor has three windings like an induction motor or a permanent magnet synchronous motor.as given in paper [9],the torque equation of a BLDC motor is given by formula (4), $\tau_{d}$ is the developed torque of the motor, $\omega_{r}$ is the rotor speed, $k_{t}$ is the torque constant and $\lambda_{i}$ is the flux linkage.

$$
T_{e}=\frac{e_{a} i_{a}+e_{a} i_{a}+e_{a} i_{a}}{\omega_{r}}=k_{t}\left(\lambda_{a} i_{a}+\lambda_{b} i_{b}+\lambda_{c} i_{c}\right)
$$

The motion equation is ${ }^{[9]}$ :

$$
T_{e}=J \frac{d \omega_{r}}{d t}+B \omega_{r}+T_{l}
$$

where $J$ is the inertia, $B$ is the damping ratio and $T_{l}$ is the load torque. 

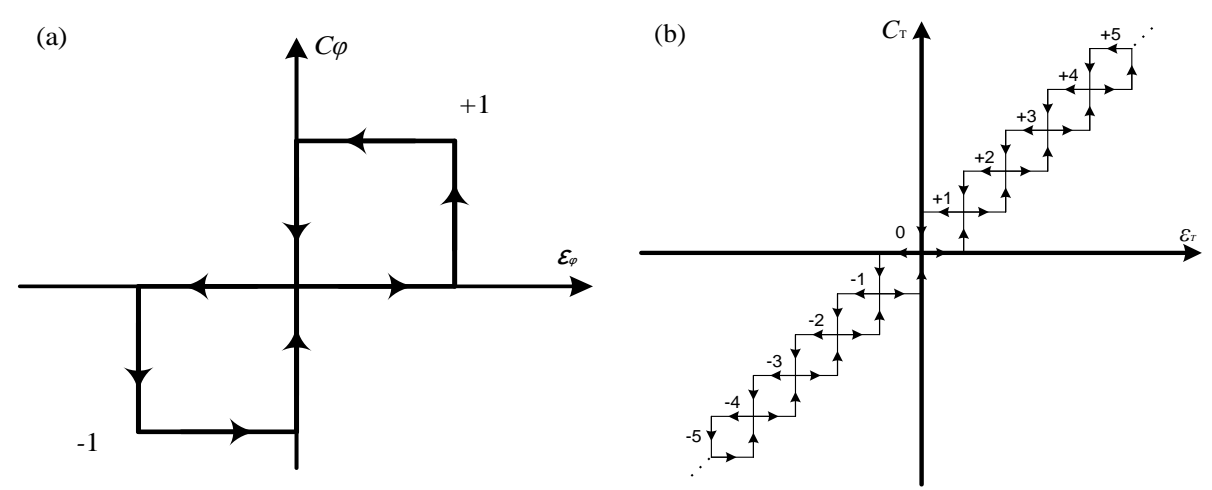

Fig.4 Flux and torque hysteresis block:(a) flux comparator (b) torque compatator

With the torque equation given above, the BLDC motor torque can be adjust by a torque camparator and a flux comparator which is shown in Fig.4. Using the hysteresis comparator outputs torque $C_{T}$, the flux $C \varphi$ and the stator flux sextor $S$,the proper output vector can be chosen to correct the error due to the relation in the switching table(shown in Table.1 ). The switching configuration is made step by step. The selection of a voltage vector at each cycle period $T_{e}$ is carried in order to maintain the flux and torque within the limits of two hysteresis bands.

Table 1 the switching table of five-level inverter

\begin{tabular}{cccccccccc}
\hline \multirow{2}{*}{$V_{x}$} & \multicolumn{8}{c}{ Swithcing state } & \multirow{2}{*}{$S_{x}$} \\
\cline { 2 - 10 } & $S_{1}$ & $S_{2}$ & $S_{3}$ & $S_{4}$ & $S_{5}$ & $S_{6}$ & $S_{7}$ & $S_{8}$ & \\
\hline$V_{d c} / 2$ & 1 & 1 & 1 & 1 & 0 & 0 & 0 & 0 & 2 \\
\hline$V_{d c} / 4$ & 0 & 1 & 1 & 1 & 1 & 0 & 0 & 0 & 1 \\
\hline 0 & 0 & 0 & 1 & 1 & 1 & 1 & 0 & 0 & 0 \\
\hline$-V_{d c} / 2$ & 0 & 0 & 0 & 1 & 1 & 1 & 1 & 0 & -1 \\
\hline$-V_{d c} / 4$ & 0 & 0 & 0 & 0 & 1 & 1 & 1 & 1 & -2 \\
\hline
\end{tabular}

\section{Simulation Results}

The multilevel SVM-DTC strategy has been tested by simulations. The BLDC motor parameters are: $R_{s}=4.85 \Omega, R_{r}=3.805 \Omega, L=27.4 \mathrm{mH}, J=31 \mathrm{~g} \cdot \mathrm{m}^{2}, V_{d c}=300 \mathrm{~V}$ and $\omega_{r}=1420 \mathrm{rpm}$. The requested space voltage vector, demanded by the SVM-DTC strategy, is assured as shown by the line voltage in Fig.5. Thus, if compared with a two-level SVM-DTC strategy, the waveform applied to the motor terminals is more approach to sine wave for three-, five- and seven-level inverter. Furthermore,the hanmonic is also reduced. 




Fig. 5 The output voltage waveform and the FFT analyses of multilevel inverter

Fig.6 shows the Flux Trajectories of three-, five- and seven- level inverters fed DTC Induction motor drive. From the simulation results flux trajectories is a circle and answers more quickly in seven-level as compared to three- and five-level inverter to BLDC motor drive.

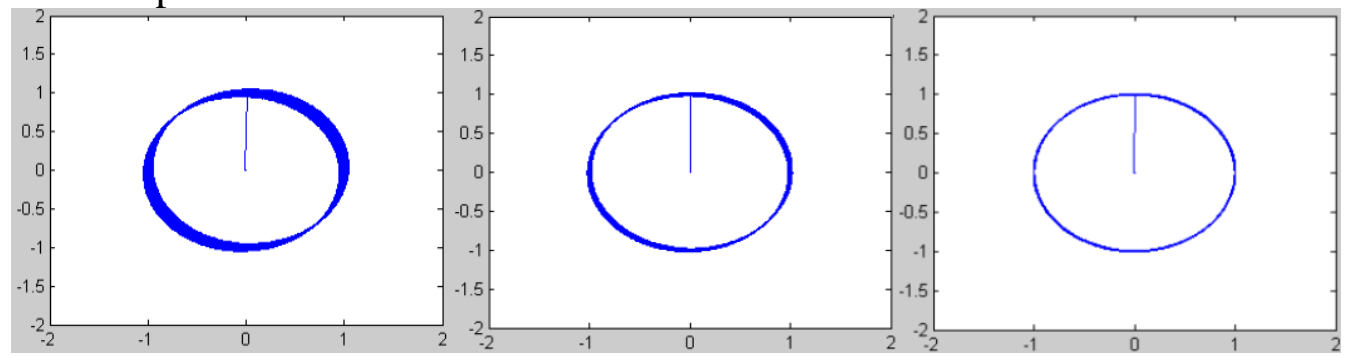

Fig. 6 The Stator flux trajectory of three-level, five-level and seven-level

\section{Summary}

The analysis of multilevel technology for electric vehicle BLDC motor Drive has been presents in this paper. The three-level, five-level and seven-level inverter are discussed, and the general method of SVM-DTC for multilevel inverter are given. To testify the given method the simulation are built using MATLAB/Simulink software. The output harmonic of the multilevel inverter are compared, and the flux linkage of BLDC motor driving by different level inverter are obtained. The results illustrated that the proposed SVPWM and DTC method can deduce the output harmonic and improve the motor control performance. It meanwhile using multilevel technology can increase the efficiency of the electric vehicle driving system.

\section{Acknowledgements}

This paper is Graded by the Nature Scientic fundmental of Jiangxi Province in China 20122BAB206033.

\section{References}

[1] Leon M.,Fangzheng Peng,Tomas Habetler.Multilevel Inverters for Electic Vehicle Applications [J]. WPET,1998,pp.79-84 
[2] Mohan M. Renge,Hiralal M. Suryawanshi.Five-Level Diode Clamped Inverter to Eliminate Common Mode Voltage and Reduce dv/dt in Medium Voltage Rating Induction Motor Drives[J]. IEEE TRANSACTIONS ON POWER ELECTRONICS, 2008,VOL. 23, NO. 4, pp.1598-1607

[3]vinod Kr Singh Patel, A.K.Pandey. Modeling and Simulation of Brushless DC Motor Using PWM Control Technique[J].International Journal of Engineering Research and Applications, 2013,Vol. 3, Issue 3, pp.612-620

[4] Jose Rodriguez, Jih-Sheng Lai, Fang Zheng Peng.Multilevel Inverters: A Survey Topologies of Controls and Applications[J]. IEEE TRANSACTIONS ON INDUSTRIAL ELECTRONICS, 2002,Vol. 49, No. 4, pp.724-738

[5]Yousif Ismail, Al Mashhadany. High-performance multilevel inverter drive of brushless DC motor[J].International Journal of Sustainable and Green Energy,2015,4(3-1),pp.1-7

[6]Farid Khoucha, Khoudir Marouani,etc.A 7-Level Single DC Source Cascaded H-Bridge Multilevel Inverter with a Modified DTC Scheme for Induction Motor-Based Electric Vehicle Propulsion[J].International Journal of Vehicular Technology,2013,pp.1-9

[7] X. Li, R. Duke and S. Round. Development of a three-phase three-level inverter for an electric vehicle. Australasian Universities Power Engineering Conf., Australia,1999, pp.247-251

[8] NAZIHA AHMAD AZLI, NORJULIA MOHD NORDIN, NIK RUMZI NIKIDRIS.DIRECT TORQUE CONTROL OF MULTILEVEL INVERTER-FED INDUCTION MACHINES-A SURVEY[J].Journal of Theoretical and Applied Information Technology,2012,Vol. 41 No.2, pp.181-191

[9]G. Laxminarayana ,K.pradeep.Comparative Analysis of 3-, 5- and 7-Level Inverter Using Space Vector PWM[J].International Journal of Advanced Research in Electrical, Electronics and Instrumentation Engineering,2013,Vol. 2,pp.3233-3241

[10] Yongjin Kang ,Ji-Yoon Yoo. Switching Pattern-Independent Simulation Model for Brushless DC Motors[J]. Journal of Power Electronics,2011, Vol. 11, No. 2, pp.173-178

[11]Dr. Jagdish Kumar.THD Analysis for Different Levels of Cascade Multilevel Inverters for Industrial Applications[J].International Journal of Emerging Technology and Advanced Engineering,2012,Vol.2, Issue.10,pp.237-244. 